\title{
Alain Badiou y la filosofía como presentación didáctica del ser en común
}

\author{
Alain Badiou and philosophy \\ as didactic presentation of the being in common
}

Wenceslao García PuChades

Universidad Politécnica de Valencia

RESUMEN. El siguiente trabajo aborda la relación del filósofo francés Alain Badiou con la cuestión de lo común. Partiendo del modo en que algunos filósofos del siglo XX han tratado esta cuestión, proponemos una lectura de la obra de Alain Badiou como proyecto que pretende recuperar la filosofía como práctica universal e igualitaria para el aprendizaje del pensamiento del ser en común tomando como paradigma el lenguaje formal de las matemáticas y el lenguaje poético.

Palabras clave: Badiou, ser en común, educación, acontecimiento, matemáticas, poesía

Poco se ha dicho hasta ahora de la relación de la filosofía de Alain Badiou con lo común que no esté vinculado a sus textos políticos y a su proyecto para recomenzar la hipótesis de comunismo (Badiou, 2008, 2009; Bosteels 2011; García Puchades, 2012; McGee 2009: 156-93). Sin embargo, a nuestro parecer, es posible leer la obra central del filósofo francés como una reflexión más amplia acerca de esta cuestión, siguiendo así la línea de algunos teóricos contemporáneos.

Al comienzo de su Filosofía de la deserción, Pelbart expone cómo varios autores contemporáneos -Toni Negri, Giorgio Agam-
ABSTRACT. The following paper deals with the relationship of the French philosopher Alain Badiou with the question of the common. Taking as a starting point the way some philosophers from the 20th century have tackled this subject, we propose an interpretation of Badiou's work as a project that intends to recover philosophy as universal and egalitarian practice for learning the thought of being in common, taking as a paradigm the formal language of mathematics and poetic language.

Key words: Badiou, being in common, education, event, maths, poetry

ben, Paolo Virno, Jean-Luc Nancy o Maurice Blanchot, entre otros- declaran que hoy en día vivimos una crisis de lo «común». Las formas que antes parecían garantizarles a los hombres un «contorno común», un «lazo social», han entrado en colapso, desde la esfera pública hasta los modos de asociación más consagrados: comunitarios, nacionales, ideológicos, partidarios, sindicales, etc. Todas estas formas de experimentación de lo colectivo se habían caracterizado por haber secuestrado lo común bajo formas unitarias, totalizadas y transcendentalizadas. De manera que, en una sociedad en la que los gran- 
des relatos parecen haber llegado a su fin, tales figuraciones de lo común comienzan a aparecer como lo que son: «puro espectro» (Pelbart, 2009, 21-2).

Sin embargo, afirma el filósofo húngaro, a pesar de esta percepción espectral de lo común, hoy en día dicho concepto prevalece como el espacio productivo por excelencia. El llamado trabajo inmaterial, la producción posfordista o el capitalismo cognitivo son fruto de la emergencia de lo que nos es más común, esto es, nuestra capacidad de comunicar, relacionarse, asociar, cooperar, compartir y forjar nuevas conexiones. Lo común hoy pasa por la apropiación de este bios social, por el agenciamiento de la producción de vida común que constituye el núcleo de la producción económica, materia o inmaterial. Se trata de poner en común lo que nos es común, es decir, la «potencia de vida», el «biopoder», la «potencia de invención» (Pelbart, 2009: 23-4; cf. Agamben, 1998; Lazzarato, 2001). El término «multitud» parece recoger bien esta concepción de lo común como potencia desmedida constituida por una multiplicidad de singularidades en variación continua que se opone a un poder soberano que pretende contenerla (Virno, 2003; Hardt y Negri, 2004, 2005). Lo común, concebido como fundamento virtual de esta vitalidad social pre-individual, como heterogeneidad no totalizable, se aleja de las figuras abstractas - estado, familia, nación, etc.que pretenden unificarlo. De ahí que la experiencia de lo común hoy, en tanto potencia de vida, pasa por una resistencia a ser pensado desde esas instancias transcendentes que lo clausuran. Con otras palabras, tras la muerte de los grandes relatos, sólo tiene sentido aproximarse al pensamiento de lo común desde el plano de la inmanencia.

\section{El pensamiento de lo común en inmanencia: la filosofia vitalista}

Desde nuestro punto de vista el pensamiento de lo común en inmanencia se hace eco, de alguna manera, de las investigaciones que en este ámbito realizaron filósofos como Nietzsche (con su «voluntad de poder»), Bergson (con su «impulso vital»), Heidegger (con su «diferencia ontológica») y, principalmente, Merleau-Ponty. Tal y como afirma Leonard Lawlor (2006), en la formación de lo que se ha denominado «vitalismo» (haciendo uso del término bergsoniano «impulso vital» [élan vital]) resulta fundamental la revisión que Merleau-Ponty realizó de la dialéctica hegeliana, de la fenomenología de la conciencia husserliana y de la ontología existencialista heideggeriana. Para Lawlor (op. cit., 3) si queremos concebir el principio que fundamenta el «vitalismo» debemos obedecer al imperativo negativo que nos enseña Merleau-Ponty: el principio no debe ser ni positivo ni negativo, ni infinito ni finito, ni interno ni externo, ni objetivo ni subjetivo, ni idealista ni realista, ni teológico ni mecanicista, ni determinista ni indeterminista, ni humanista ni naturalista, ni metafísico ni físico. Caer en alguno uno de estos dos extremos es precisamente lo que no debemos hacer (Merleau-Ponty, 1956-1957, 203). Lo que la filosofía de Merleau-Ponty nos enseña es que el principio de la vida no debe ser pensado como una separación entre alguno de estos dos polos, ni tampoco como una coincidencia. La formula positiva para el imperativo merleaupontiano es que dicho principio debe ser pensado como un «hiatus», un «écart», que mezcla a los dos extremos juntos (Lawlor, op. cit., 164). 
La referencia a este término como principio del pensamiento vitalista aparece de manera explícita en varias de las obras de la filosofía contemporánea. Así Michel Foucault, en Las palabras y las cosas, hablará de un «rodeo [écart], ínfimo pero invencible, que reside en el "y" del retroceso y del retorno, del pensamiento y de lo impensado, de lo empírico y de lo trascendental, de aquello que pertenece al orden de la positividad y de aquello que es del orden de los fundamentos» (Foucault, 2002 [1966], 330). También Jacques Derrida en De la gramatología hablará de «una mínima diferencia [différence]; esta pequeña diferencia -la visibilidad, el espaciamiento, la muerte- es indudablemente el origen del signo y la ruptura de la inmediatez» (Derrida, 2005 [1967], 295). Finalmente Gilles Deleuze también se referirá en Lógica del sentido a este «hiatus» o «écart» como «la distancia [distance] infinitiva, [...] desplazamiento [déplacement $]$ de la perspectiva, diferenciación de la diferencia» que caracteriza a «los acontecimientos puros» (Deleuze, 2005 [1969], $211,212)^{1}$.

Vemos por tanto como para la filosofía vitalista el plano de inmanencia donde se experimenta lo común como potencia de vida o de innovación tiene su fundamento en este límite acontecimiental que acerca y distancia un adentro y un afuera. Un límite, sin embargo, tal y como nos dice Jean-Luc Nancy, que carece de lugar: «Lo repito: sólo el límite es común, y el límite no es un lugar, sino la partición de los lugares, su espaciamiento. No hay lugar común» (Nancy, 2001, 137). Nancy, de la misma manera que Deleuze, afirmará que el límite en el que se ubica la potencia del «en-común» sólo se puede experimentar como acontecimiento:
«[...] el acontecimiento no es lo que tiene lugar, sino la llegada de un lugar, de un espacio-tiempo como tal, el trazado de su límite, su exposición». El «ser-en-común» que no es un «ser común» y que la propia comunidad no limita, se articula en la interrupción y por la interrupción misma (op. cit., 170, 117). Con otras palabras, el espaciamiento del «en-común» se presenta como «retirada» misma de la comunidad entendida como una totalidad; una disyunción «encapsulada» en el «fenómeno de una sorpresa disruptiva» que a su vez constituye la exposición de la apertura misma en cuanto momento y acontecimiento (Marchart, 2009, 103; Cfr. Lacoue-Labarthe y Nancy, 1997, 119).

La sutura poética de la filosofía vitalista

Llegados a este punto la cuestión que queda por resolver es: ¿Cómo ha sido capaz la filosofía vitalista de presentar el acontecimiento como fenómeno que expone la potencia creadora del «ser-en-común», si toda presentación es presentación de $u n$ objeto y, por tanto, sometimiento de éste a la norma de la unidad? ¿Cómo exponer lo que es común conservando su multiplicidad si, tal y como nos recuerda Heidegger, aquello por lo cual «lo que es» es lo que es, es también aquello por lo que es uno? (Badiou, 2002, 25). Una vez más: ¿Cómo es posible presentar el «en-común» de la apertura sin que quede clausurada en el propio acto de exposición? Para el filósofo francés Alain Badiou la presentación de lo «múltiple-sinunidad» solamente ha sido posible gracias a la «sutura» del argumento filosófico al lenguaje poético, señalando a Heidegger como el referente de «haber cruzado la crítica pro- 
piamente filosófica de la objetividad con su destitución poética» y de «entregar la filosofía a la poesía» (1990a, 53, cursiva en el original; 2003a, 88).

Sin embargo el filósofo francés no se refiere aquí a toda la poesía, ni a todos los poetas, sino a aquellos «cuya obra es inmediatamente reconocible como una obra de pensamiento». La «edad de los poetas», nos dice Badiou, marca una época, entre Hölderlin y Paul Celan, en la que la poesía ofrece a la filosofía «la destitución de la categoría de objeto, y de objetividad, como formas necesarias de la presentación» (1990a, 52; cf. 1992). El procedimiento complejo que pone en práctica el poeta de esta época para enunciar la disolución de las identidades y la apertura del ser es una operación metafórica por la que se destituye la pareja de términos objeto/sujeto. Esta operación puede ser de dos tipos: de carencia o de exceso. Así, por un lado el «objeto está, o bien sustraído, retirado de la presencia por su propia autodisolución (el método de Mallarmé), o bien extirpando de su dominio de aparición, desarticulado por su excepción solitaria, y vuelto, a partir de ese momento, substituible a cualquier otro (el método de Rimbaud)»; y por otro lado «el sujeto es invalidado, ya sea por ausentamiento (Mallarmé), o por pluralización efectiva (Pessoa, Rimbaud)» (Badiou, 1990a, 56; cf. 2009b, 61-92).

Para Badiou la «edad de los poetas», a través de estas dos operaciones, nos presenta al poema como ese espacio singular en el que las categorías de «vacío» e «infinito» confluyen justo en ese punto donde su sentido se presenta como falta y exceso múltiple.

Por un lado, Mallarmé nos enseña que el poema no se presenta como una colección de objetos. No se trata ni de una descripción ni de una expresión, sino de una operación de presentación y, por tanto, también de un acontecimiento. El imperativo de la desobjetivación es simple: «entrar en el poema, no para saber de qué habla, sino para pensar qué pasa en él». Y para ello el poeta propone una «operación oblicua de captura» a través de palabras «alusivas, nunca directas». Así, la disolución del objeto a través de la «transposición» de palabras se verá acompañada por la existencia de un enigma, un «hermetismo», que invita al lector a entrar en él para alcanzar su propia operación de presentación (Badiou, 2009b, 76-7).

Por otro lado tenemos a Pessoa, «el poeta de la equivocidad» y de la «heteronomía». Para Badiou, el poema de Pessoa se muestra como un «dispositivo de pensamiento» que conforma «una especie de lugar ideal», donde las correlaciones y las disyunciones entre figuras heterónomas liberan «al infinito la energía del poema». Se trataría de presentar el poema como ese elemento singular que muestra «la contingencia de lo múltiple» para luego incitar a su reconstrucción infinita ( $o p$. cit., 90-2).

Desde nuestro punto de vista buena parte de la filosofía del último siglo ha acudido al carácter aporético del lenguaje de la poesía, la literatura y el arte en general para tratar de presentar el «ser-en-común» sin clausurar su carácter múltiple y abierto. Para ello ha utilizado, como dos momentos de un mismo movimiento retórico, estrategias que vacían o exceden el sentido del «en-común» o «comunidad» del ser. Estas estrategias se encontrarían presentes, por ejemplo, en la exposición de la «comunidad Acéphale» de Bataille (1937), la «comunidad negativa», la «comunidad inconfesable» o la «comunidad de amantes» de Maurice Blanchot (1999 
[1983]), la «comunidad que viene» de Agamben (2006 [1990]), la «comunidad desobrada» 0 «comunidad afrontada» de JeanLuc Nancy (2001 [1986]; 2002 [2001]). En nuestra opinión todas ellas podrían entenderse como intentos de desobjetivizar lo común a través del uso de retóricas de la carencia o del exceso. Como ejemplo de las primeras encontraríamos aquellas operaciones de deconstrucción del concepto «comunidad» que pretenden mostrar que éste, entendido como comunión, fusión o unidad, nunca ha existido. La presentación de la comunidad en su ser-contingente le incorpora un elemento de falta que nos impide hablar de ella como un objeto dado. «La comunidad no ha tenido lugar» afirma Nancy $(2001,29)$. De manera que la comunidad perdida nunca ha pasado de ser un mero fantasma. En otros términos más paradójicos, la comunidad sólo ha sido pensable como afirmación de su propia muerte ${ }^{2}$.

A la presentación del concepto de «comunidad» como ausencia de comunidad, estos argumentos añaden una segunda operación que buscan redimirlo presentándolo como la infinita potencia relacional de las singularidades sin forma. Para ello pondrán en juego diferentes figuras, reales o de ficción, que ejemplifican no sólo la resistencia a una vida envenenada por formas comunitarias, sino la llamada a una vida vivida en inmanencia y fundamentada en la capacidad para crear nuevas vías de asociación sin forma que preserven la singularidad cualquiera y eviten la exclusión (Deleuze, 1995; Agamben, 2006) ${ }^{3}$.

Sin embargo para Alain Badiou, la sutura del argumento filosófico a la metáfora poética ha acabado con la esencia «sistemática» de la filosofía y, por tanto, con la posi- bilidad de la filosofía misma (1990a, 44-5). Tal y como hemos mostrado anteriormente, el precio que paga la filosofía vitalista para presentar la potencialidad infinita del ser-encomún es una renuncia a la presentación inteligible de lo común. Lo común en inmanencia queda reducido a ese momento acontecimiental, azaroso y efímero imposible de exponerse al pensamiento más que a través de un lenguaje críptico, enigmático y hermético. Para Badiou esta exposición misteriosa impide una de las tareas fundamentales de la filosofía, a saber, su didáctica universal e igualitaria. Veamos con más detalle esta afirmación.

\section{La filosofía como didáctica universal para identificar la existencia del ser-en-común}

Desde nuestro punto de vista, buena parte de la obra del filósofo francés Alain Badiou puede entenderse como un proyecto para recuperar la filosofía como una práctica didáctica que pretende transmitir la idea de que cualquiera es capaz de identificar por sí mismo un procedimiento infinito de creación en común, forzando a decidir su participación en él ${ }^{4}$. Esta concepción de la filosofía, con claras influencias de los Diálogos platónicos, está condicionada por dos principios: el principio de igualdad de opinión y el principio de igualdad de existencias (2011, 35-7). El primero declara el componente democrático de la tarea filosófica en la medida en que permite que cualquier individuo exprese su opinión. El segundo declara su componente universal, en la medida en que cualquier individuo debe tener acceso a corroborar por sí mismo aquello que se dice en la escena filosófica. La síntesis de estos dos principios acaba subordi- 
nando la regla de igualdad de opiniones a la regla de evaluación objetiva, la cual condicionará la práctica filosófica a la existencia real de un cuerpo compartido que sirva de referente para corroborar los argumentos. Nos encontramos, por tanto, con dos principios que definen qué es una situación filosófica para Badiou. El primero: nadie participa en la escena filosófica si no acepta la regla de evaluación objetiva de los argumentos; y el segundo: toda práctica filosófica es pensamiento de una situación determinada a través de un cuerpo compartido.

A juicio de Badiou la filosofía vitalista fracasa en el cumplimiento de estos principios. En primer lugar, fracasa al ocultar lo común en el ámbito misterioso de la potencialidad vital de creación. Al hacer esto, su preocupación no es tanto presentar lo común como cuerpo compartido sin comunión -el «hay» de lo común-sin-uno-, sino presentar su carencia de sentido. Tal y como hemos visto, esta tarea se ve impelida a acudir al lenguaje como única vía de acceso a él. Así la filosofía vitalista se suma a la tendencia que ha dominado en la filosofía del siglo XX, a saber, la preocupación por una meditación sobre el lenguaje, sobre sus capacidades, sus reglas, y sobre lo que el lenguaje autoriza en lo que respecta al pensamiento de lo común, olvidando la cuestión de su existencia fáctica (Badiou, 2010a, 52-6).

En segundo lugar, la filosofía vitalista, en su búsqueda de un lenguaje adecuado para acceder a lo abierto del ser-en-común, ha encontrado en el lenguaje poético y artístico las operaciones retóricas adecuadas para esta tarea. Este hecho ha contribuido a alejar el pensamiento filosófico de esa práctica discursiva, universal y objetiva -a la que Platón denominaba «dianoia»-(Badiou, 2009, 69), para acercarlo a una práctica interpretativa, particular y subjetiva que despliega el lector en su libre juego con el texto poético-filosófico. Nos encontramos, por tanto, en una situación en la que el argumento filosófico aparece subordinado a la regla sofista de la igualdad de opiniones. Para el sofista toda opinión es legítima ya que no hay lenguajes universales, sólo hay multiplicidad de juegos de lenguaje, pluralidad de registros del pensamiento y de la acción, y diversos y heterogéneos registros del sentido (Badiou, 2003a, 66; 2010a, 52-4). Frente al argumento sofista de la pluralidad y relatividad de las opiniones, la filosofía para Badiou debe reivindicar un argumento objetivo e universalidad que dé cuenta de la existencia de cuerpos-en-común-sin-unidad. El filósofo reivindicará como paradigma de esta argumentación el lenguaje formal de las matemáticas, en concreto, la teoría axiomática de conjuntos y la teoría de las categorías.

\section{La presentación objetiva de la existencia del ser-en-común}

Ya argumentamos anteriormente cómo para Badiou la necesidad de universalizar el acto filosófico obligaba a construir una situación en torno a la existencia de un material compartido. En otras palabras dijimos que la condición para que la afirmación filosófica del «hay» de lo común-sin-uno pueda ser corroborada por cualquiera es su existencia corporal. Esto implica la tarea previa de prescribir una situación material concreta en torno a la cual se puede realizar la práctica filosófica.

El filósofo comienza su tarea con la «decisión axiomática» de «contar-por-uno» una situación del presente (Badiou, 2002, 93; 
2007a, 33-41). Para ello, tomando como modelo la teoría de conjuntos, debe prescribir los axiomas fundamentales de su práctica. Tal y como ha mostrado el sistema axiomático de Zermelo-Fraenkel, todo conjunto puede definirse con el axioma de conjunto vacío en el que se postula la unidad elemental de existencia-y el axioma de extensionalidad -en el que se postula la regla de pertenen$\mathrm{cia}^{5}$. El resto de axiomas son axiomas secundarios u operativos - de subconjuntos, de unión, de separación, de reemplazamiento, de fundación, de infinito y de elección-que hacen referencia de una manera $u$ otra a la existencia de estos axiomas fundamentales. Así, de la misma manera que las investigaciones de la teoría de conjuntos tienen origen en la declaración estos axiomas, la tarea del filósofo debe comenzar con la declaración de las unidades elementales que pertenecen a la situación filosófica. Posteriormente podrá deducir otras operaciones que le permitirán clasificar y ordenar dichos elementos. Sólo a través de esta operación axiomática es posible presentar una situación filosófica para poder argumentar con objetividad lógica la existencia o no de cuerposen-común.

El propio Badiou realiza esta tarea prescribiendo cuatro ámbitos o situaciones en los que se puede desarrollar la práctica filosófica: el arte, la política, la ciencia y el amor. Cada uno de ellos especifica la materia susceptible de producir un procedimiento creativo en común, a saber, la diferente materialidad de las obras de arte, el cuerpo de los trabajadores, la letra y los números de las teorías científicas, y el cuerpo de los amantes (Badiou, 1990a, 17; 2009, 57; 1990b, 56; 1996-98; 2003a, 252). Vemos, por tanto, cómo Badiou condiciona la tarea filosófica de identificación de la existencia de cuerpos-en-común a estos cuatros ámbitos materiales.

Ya vimos anteriormente cómo esta tarea estaba sometida a la aceptación de la regla de evaluación igualitaria de los argumentos. De acuerdo con esta regla, cualquier participante de la escena filosófica debería ser capaz de mostrar mediante un argumento objetivo la existencia de cuerpos que evidencian lógicas genéricas o en-común. Ahora bien, para Badiou -y en este punto coincidirá con la filosofía vitalista - la lógica del en-común, ya que es una lógica consecuencia de un acontecimiento, carece de sentido para el régimen del saber dominante (Badiou, 2009a, 193). Desde este punto de vista la práctica filosófica se debe desarrollar a partir de diferentes argumentos que fuerzan a la identificación y al reconocimiento objetivo del sin-sentido de los procedimientos en común que existen en el arte, la ciencia, la política y el amor sin necesidad de recurrir a las categorías establecidas por el saber dominante.

Esta tarea descriptiva encuentra su modelo en la teoría de las categorías matemáticas y ha sido expuesta con detalle por $\mathrm{Ba}$ diou en el apartado dedicado al método de la fenomenología objetiva en Lógicas de los mundos (2008b, 219-60). A través de dicho método el filósofo francés nos presenta un modelo para argumentar de manera objetiva la existencia de un cuerpo en-conjunto a través del estudio fenomenológico de una situación determinada. Partiendo de la prescripción axiomática de una situación artística, política, científica o amorosa concreta, esta metodología nos propone describir las propiedades dominantes para cada una de ellas, y conocer así las lógicas que condi- 
cionan el aparecer de los cuerpos de dichos «mundos». Una vez realizada esta descripción será posible identificar con objetividad los procedimientos en-común existentes. Estos procedimientos, ya que son lógicamente fieles a la lógica de un acontecimiento, deberían aparecer en la situación presentada como el «reverso» lógico inmanente de las propiedades dominantes anteriormente descritas (2008b, 154, 158, 161, 156, 188). Así, en tanto «reverso» lógico de lo máximamente existente, los cuerpos de este colectivo aparecerán como carentes de propiedades. Sin embargo esta carencia no será más que una ilusión, pues lo que realmente evidencia es la presencia de un nuevo orden lógico del aparecer, a saber, la lógica en-común del ser singular cualquiera.

Si aplicamos esta metodología a cada uno de los ámbitos prescritos por Badiou estos procedimientos en-común aparecerían de cuatro formas diferentes: en cada una de las artes como una nueva configuración artística que reivindica la potencialidad de las formas para buscar nuevas vías de asociación más allá del establishment; en la política como un movimiento emancipador de las masas trabajadoras y populares que reivindica su poder para organizarse sin necesidad de estado, nación, comunidad o partido político; en la ciencia como un nuevo postulado o teorema que reivindica el poder de las letras y números para construir nuevos modelos epistemológicos más allá de lo reconocido por la comunidad científica. Y finalmente en el amor como el comienzo de una vida en pareja que bajo su reconocimiento mutuo e igualitario evitan apelar a la figura del contrato matrimonial o la fusión romántica (cf., Badiou, 2010b, 128).
Recapitulemos. En los apartados anteriores hemos mostrado cómo el proyecto de Alain Badiou puede entenderse como una propuesta para recuperar la práctica filosófica como escena educativa que nos enseña un método universal e igualitario para presentar con sistematicidad y objetividad que no sólo existen cuerpos comunitarios o individuales, sino cuerpos-en-común. Partiendo de las dificultades didácticas que ha supuesto para gran parte de la filosofía del siglo XX suturar esta tarea al lenguaje poético, el filósofo francés propone como modelo el lenguaje de las matemáticas. La teoría axiomática de conjuntos y la teoría de categorías nos ofrecen las operaciones adecuadas para desarrollar la práctica filosófica como escena igualitaria que posibilita a cualquiera el encuentro con la potencia de ser-en-común de los cuerpos. Ahora bien, para Badiou este giro del argumento filosófico a las matemáticas no implica un rechazo del lenguaje metafórico y poético, sino su tratamiento conjunto: «La filosofía imita [...] o toma prestados dos procedimientos de verdad: la matemática, paradigma de la prueba, y el arte, paradigma del poder subjetivante» (Badiou, 2003a, 60). Veámoslo con más detalle.

\section{La presentación persuasiva y afectiva de la existencia del ser en común}

Después de lo dicho hasta ahora podría pensarse que el proyecto de Badiou relega la práctica filosófica a una experiencia meramente intelectual a través de un lenguaje formal. Sin embargo, para el filósofo francés, una escena filosófica adecuada debe posibilitar que el encuentro con los procedimientos-en-común sea una exposición placentera y persuasiva. Tomando como modelo 
los Diálogos de Platón, Badiou propone que la filosofía acuda a la fábula, el mito, la parábola y la imagen literaria como figuras en las que buscar la analogía y la semejanza estructural relativa a los conceptos que pretende enseñar. En otras palabras, a través de sus Diálogos, Platón nos dice que es posible acudir al poder persuasivo del lenguaje poético siempre y cuando éste contribuya a la tarea filosófica. Badiou llamará a este uso filosófico de la literatura «refuerzo táctico» (2007b: 59) ${ }^{6}$.

Para el filósofo francés la función táctica de la literatura aparece dividida en los Diálogos de Platón en una función mediadora y otra tipificadora. Encontramos la primera función cuando Platón utiliza fábulas, parábolas e imágenes para introducirnos en «un problema evidentemente complicado, o una síntesis difícil que hace que no podamos desplazar o reducir conceptualmente la cosa» (2007b: 76). Este uso mediador de la literatura se fundamenta en una capacidad de seducción del arte que el concepto filosófico no posee. De manera que hay una utilización de esta seducción para que el lector ingrese en la cuestión que plantea el filósofo. Para Badiou esta apropiación filosófica de la literatura encuentra su referente en el modo en que Heidegger utiliza a los poetas: «[...] la utilización literaria de los poetas por Heidegger consiste en tratar de construir una cuestión utilizando la seducción literaria como mediación» (op. cit., 62).

Puesta al servicio del proyecto filosófico de Badiou, la función mediadora del lenguaje artístico debe ser entendida como el uso del poder de seducción de determinadas figuras poéticas utilizadas para el reconocimiento intelectual de los procedimientos encomún. El filósofo debe buscar en las dife- rentes artes fábulas, mitos e imágenes que posean una estructura genérica, indeterminada y siempre abierta análoga a estos procedimientos. Así, a través de este segundo acto de presentación (re-presentación) de la estructura del ser-en-común sin fin, el filósofo tratará de poner en imágenes lo irrepresentable, facilitando así la incorporación a la escena filosófica? ${ }^{7}$.

La segunda función que se derivaba del uso táctico de la literatura en los Diálogos era la función tipificadora. En ellos Platón exponía su filosofía mediante el enfrentamiento de personajes sin que haya medida común alguna que permita mediar entre las posiciones que cada uno defiende. De manera que la discusión no es tal, sino una confrontación entre posturas extrañas. Platón encontró como referente de este estilo el género de la narrativa teatral. Para Badiou lo realmente significativo de esta operación es la presentación «de un solo golpe» de aquello que la filosofía no puede exponer sino sucesivamente: «Hay en la filosofía un orden temporal de sucesión de ideas, en tanto que en la literatura existe la capacidad de reunir todo eso en una sola figura -en este caso en un personaje de teatro» $(2007 b, 64)$. La filosofía utiliza la construcción de personajes para crear un «tipo» capaz de reunir «en una figura lo que el concepto no puede exponer sino pedazo por pedazo» (64). Badiou pondrá como ejemplo de la construcción de una «ficción típica» el uso que hace Hegel de la Antígona de Sófocles en La Fenomenología del Espíritu. Desde el punto de vista de Badiou, Hegel utiliza la figura de Antígona como una suerte de «concentración conceptual» (64).

Esta figura del personaje entendida como «concentración conceptual» tiene 
fuertes resonancias con aquello que Deleuze y Guattari denominaron «personaje conceptual». Tal y como estos filósofos exponían en ¿Qué es la filosofia?, los «personajes conceptuales» representan los movimientos del pensamiento filosófico de un autor en lo que se refiere a un problema filosófico o a la creación de un concepto (1997, 65). Y dado que la creación de un «concepto» está constituida por «un número finito de componentes heterogéneos» (op. cit., 22, 23, 26), el filósofo podrá representar cada uno de esos componentes a través de diferentes personajes. Así, mientras que Deleuze denomina «personaje conceptual» a la síntesis de diferentes «trozos o componentes de otros conceptos» (op. cit., 23), Badiou denomina «ficción típica» a «aquello que reúne en una unidad nueva multiplicidad de determinaciones conceptuales» (2007b: 64).

Por otro lado, Badiou también coincidirá con Deleuze al afirmar que el filósofo se apropia de «figuras estéticas» o «afectivas» propias del arte para ponerlas al servicio del concepto filosófico. Podríamos decir que los términos «personaje conceptual» de Deleuze o «ficción típica» de Badiou nombran la apropiación por parte del filósofo de una figura retórica capaz de producir afectos para ponerlos al servicio del pensamiento. En otras palabras, el «personaje conceptual» posibilita la transferencia de la «potencia de afecto» de la figura estética al concepto (cf., Deleuze y Guattari, 1997, 66-8).

Ahora bien, el término «afecto» no tiene el mismo sentido en Deleuze que en Badiou. Mientras que para Deleuze un afecto es un término que designa una sensación, para Badiou designará un modo de hacer (Deleuze y Guattari, op. cit., 164; Badiou, 2008c, 313). Tal y como Badiou expuso en
Teoría del sujeto, los afectos no se refieren a experiencias subjetivas sino al «modo de hacer» de un individuo «afectado» por un acontecimiento. «Afecto» no es más que el nombre o concepto que nos permite identificar el hacer de un sujeto de manera consistente, pudiendo reconocer un modo o estilo de actuar. No hay afecto del sujeto que no provenga del encuentro con los efectos de un acontecimiento en una situación o, lo que es lo mismo, de un proceso de creación en-común. Badiou identificaba cuatro tipos de afectos (angustia, coraje, superego o terror y justicia). Estos cuatro afectos deben ser entendidos como cuatro polos de un espacio topológico en el que ubicar diferentes tipos de discursos acerca de las orientaciones en el hacer de un sujeto ante el vacío de sentido que va ligado a este tipo de procesos. Dichos discursos, ya que identifican un modo de hacer del sujeto, podrían entenderse como «formaciones subjetivas de la ética» o «éticas del sujeto» (Badiou, op. cit., 342). De esta manera, esta concepción sui generis del término «afecto» nos permite pensar en la «ficción típica» de Badiou como una reconversión ética de los «personajes conceptuales» deleuzianos. Desde esta perspectiva es posible entender la función tipificadora del arte como la construcción de personajes o figuras éticas puesta al servicio de la tarea filosófica.

Tal y como Badiou nos ha mostrado en La Ética (2004b), cualquier situación que ha sido afectada por un acontecimiento muestra el enfrentamiento de dos «figuras tipo»: la figura nihilista del discurso dominante que se sostiene en la imagen del ser humano como mero animal guiado por la búsqueda de seguridad comunitaria y de placeres particulares efímeros; $y$ la figura heroica del dis- 
curso excepcional que se sostiene en la imagen del ser humano capaz de participar punto por punto en la creación infinita de procedimientos en-común. Esta última figura subjetiva representaría al ser humano siendo capaz de enfrentarse con valentía al vacío de conocimiento que supone el encuentro con un proceso creativo colectivo que evita caer en la nostalgia de viejas figuras, ya que el refugio en estas viejas figuras le haría someterse a la disciplina cruel y violenta de los procedimientos idealizados que van ligados a los totalitarismos del pasado (op. cit., 105-23).

Finalmente, para Badiou el segundo uso táctico del arte por parte de la filosofía consistiría en la búsqueda de personajes que «tipificaran» cada uno de estos discursos afectivos que van unidos al encuentro con un proceso creativo en común. Ahora bien, dado que estos procesos solamente se dan en cuatro ámbitos diferentes, la filosofía debe buscar en las ficciones artísticas cuatro modelos de figuras éticas contemporáneas o «figuras típicas»: la figura heroica del artista que participa en nuevas configuraciones formales haciendo frente a su adversario, a saber, la figura nihilista del artista que somete sus creaciones al espectáculo del mercado y al relativismo multicultural; la figura heroica del obrero que participa en la construcción de nuevas formas de organización política sin partido frente a su adversario, a saber, la figura temerosa del obrero que se limita a tener representación en organizaciones sindicales o parlamentarias; la figura heroica del científico capaz de buscar nuevos modelos teóricos que se opone a la figura del científico sometido a las reglas de la comunidad científica; y la figura heroica del amante capaz de comenzar un episodio amoroso fun- dado en el reconocimiento igualitario de las individualidades que se opone a la de los amantes sometidos a la figura unitaria de la comunión romántica o del contrato matrimonial $^{8}$.

En resumen, a lo largo de estas líneas hemos visto en qué medida la obra del filósofo francés Alain Badiou puede ser entendida como una propuesta de recuperación de la filosofía como práctica didáctica universal e igualitaria para el aprendizaje del pensamiento en común después de que buena parte de la filosofía del siglo XX la hubiera relegado al ostracismo. Partiendo de la crítica a la filosofía vitalista y a su sutura a la poesía como recurso para presentarnos la esencia indeterminada e infinita del ser-encomún sin comunidad, Badiou recuperará el modelo de los Diálogos platónicos y reivindicará la filosofía como una exposición didáctica fundamentada en el pensamiento universal de las matemáticas. Esto condiciona la escena filosófica a la presencia de un cuerpo común que permita que cualquiera corrobore por sí mismo los argumentos acerca de la presencia del ser-en-común. El argumento filosófico debe tomar como modelo, por un lado, la teoría axiomática de conjuntos para presentar de manera estructurada las unidades elementales materiales que pertenecen a la situación filosófica y, por otro lado, la teoría de las categorías para describir con objetivad la lógica excepcional e indeterminada de los cuerpos que constituyen un conjunto-sin-unidad. Finalmente hemos visto como este giro al lenguaje formal de las matemáticas no implica un rechazo del lenguaje poético o artístico. Sin embargo, para Badiou, el uso de este lenguaje tiene que estar condicionado al correcto desarrollo de la tarea filosófica. El argumento filosófico debe 
por tanto realizar un uso táctico del poder de persuasión a través de la mimesis del arte. Este poder de persuasión, dijimos, se encontraba en su capacidad de transferir los «efectos»y «afectos» de las figuras poéticas a las figuras conceptuales. Así, vimos como la construcción ficticia de escenarios polarizados por diferentes personajes o «figuras tipo» se mostraría como la operación más adecuada para representar los discursos afectivos que acompañan el encuentro con la novedad e indeterminación de un colectivo de seres-sin-forma, mientras que el uso metafórico de las fábulas, mitos e imágenes se mostraría como la operación más adecuada para seducirnos con la representación de su componente formal.

\section{REFERENCIAS BIBLIOGRÁFICAS}

Agamben, Giorgio (1998), Homo sacer. El poder soberano y la nuda vida, trad. Antonio Gimeno Cuspinera, Valencia, PreTextos. [Homo Sacer : Il potere soverano e la vita nuda, Torino, Giulio Einaudi, 1995]

Agamben, Giorgio (2000), «Bartleby o de la contingencia», en Preferiría no hacerlo, Valencia, Editorial Pre-Textos, pp. 93-136.

Agamben, Giorgio (2006), La comunidad que viene, trad. José Luis Villacañas, Claudio La Rocca y Ester Quirós, Valencia, Pre-Textos [La comunità che viene, Torino, Giulio Einaudi, 1990]

Badiou, Alain (1990a), Manifiesto por la filosofia, trad. Victoriano Alcantud Serrano, Madrid, Cátedra [Manifeste pour la philosophie, París, Le Seuil, 1989].
Badiou, Alain (1990b), ¿Se puede pensar la política?, trad. Jorge Piatigorsky, Buenos Aires, Nueva Visión, [Peut-on penser la politique?, París, Le Seuil, 1985]

Badiou, Alain (1992), «L'Age des poètes» en J. Rancière (ed.), La politique des poètes. Pourquoi des poètes en temps de détresse, París, Albin Michel, pp. 21-38.

Badiou, Alain (1996-98), Théorie axiomatique du sujet, Apuntes de seminario, Inédito, Transcripción online a cargo de François Duvert, <http://www.entretemps.asso.fr/Badiou/96-98.htm> [última consulta 25-09-2011].

Badiou, Alain (1998), «Le plus-de-voir. Jean-Luc Godard, Histoire(s) du cinéma», Artpress, $\mathrm{n}^{\circ}$ especial, «Le Siècle de JeanLuc Godard», noviembre; reimpreso en Cinéma, 2010, 211-9.

Badiou, Alain (2000a), «La capture cinématographique des sexes», en J. Aumon (ed.), La différence des sexes est-elle visible?, París, Cinémathèque française, 127-37; reimpreso en Cinéma, 2010, pp. 239-55.

Badiou, Alain (2001b), «Passion. Jean-Luc Godard», conferencia realizada en Nantes, noviembre 2001; transcripción en $\mathrm{Ci}$ néma, comp. Antoine de Baecque, París, Nova Éditions, 2010, pp. 263-77.

Badiou, Alain (2002), Breve tratado de ontología transitoria, trad. Tomás Fernández Aúz y Beatriz Eguibar, Barcelona, Gedisa, S. A. [Court traité d'ontologie transitoire, París, Le Seuil, 1998]

Badiou, Alain (2003a), Condiciones, trad. Eduardo Lucio molina y Vedia, México D. F., Siglo XXI editores [Conditions, París, Le Seuil, 1992]. 
Badiou, Alain (2003b), «Dialectique de la fable», en VVAA., Matrix, machine philosophique, Paris, Ellipses, 120-9; reimpreso en Cinéma, comp. Antoine de Baecque, París, Nova Éditions, 2010, 307-21].

Badiou, Alain (2004a), «El cine como experimentación filosófica» en G. YoeL (ed.), Pensar el cine 1: imagen, ética y filosofia, Buenos Aires, Manantial, 2004, pp. 23-81.

Badiou, Alain (2004b), La Ética: Ensayo sobre la conciencia del mal, trad. Raúl J. Cerdeiras, México D. F., Herder [L'Ethique: essai sur la conscience du mal, $\mathrm{Pa}-$ rís, Hatier, 1993].

Badiou, Alain (2005), «La fin d'un commencement. Notes sur Tout va bien, de Jean-Luc Godard et Jean-Pierre Gorin», L'Art du cinéma, primavera, 2005; reimpreso en Cinéma, 2010, pp. 389-402.

Badiou, Alain (2007a), El ser y el acontecimiento, trad. Raúl J. Cerdeiras, Alejandro A. Cerletti y Nilda Prados, Buenos Aires, Manantial [L'Être et l'événement, París, Le Seuil, 1988].

Badiou, Alain (2007b), Justicia, filosofía y literatura, Rosario, Homo Sapiens Ediciones.

Badiou, Alain (2008a), ¿Qué representa el nombre de Sarkozy?, trad. Iván Ortega, Pontevedra, Ellago S. L. [Circonstances 4. De quoi Sarkozy est-il le nom?, París, Nouvelles Editions Lignes, 2007].

Badiou, Alain (2008b), Lógicas de los mundos: El Ser y el acontecimiento, 2, trad. María del Carmen Rodríguez, Buenos Aires, Manantial [Logiques des mondes. L'Être et l'événement, 2, París, Le Seuil, 2006].
Badiou, Alain (2008c), Teoría del sujeto, trad. Juan Manuel Spinelli, Buenos Aires, Prometeo Libros, [Théorie du sujet, $\mathrm{Pa}$ rís, Le Seuil, 1982].

Badiou, Alain (2009a), Circonstances 5. L'hypothèse communiste, París, Nouvelles Éditions Lignes.

Badiou, Alain (2009b), Pequeño manual de inestética, trad. Lucía Vogelfang, Jorge Caputo, Marcelo Burello y Guadalupe Molina, Buenos Aires, Prometeo Libros [Petit manuel d'inesthétique, París, Le Seuil, 1998].

Badiou, Alain (2010a), La filosofia, otra vez, trad. Leandro García Ponzo, Madrid, Errata Naturae.

Badiou, Alain (2010b), Segundo manifiesto por la filosofia, trad. María del Carmen Rodríguez, Buenos Aires, Manantial [Second manifeste pour la philosophie, $\mathrm{Pa}$ rís, Fayard, 2009]

Badiou, Alain (2011). La relation énigmatique entre philosophie et politique, $\mathrm{Pa}$ rís, Germina

Bataille, George (1937), «Proposiciones» en Acéphale. Religion/Sociologie/ Philosophie, no 2, 21 de enero de 1937.

Blanchot, Maurice (2002), La comunidad inconfesable, Madrid, Arena Libro [La communauté inavouable, París, Les Éditions de Minuit, 1983]

Bosteels, Bruno (2011), The Actuality of Communism, Londres, Verso.

Clemens, J., (2005) «Doubles of nothing: The Problem of Binding Truth to Being in the Work of Alain Badiou», Filozofski Vestnik, 26(2), 21-35. 
Deleuze, Gilles (1995), «Immanence: une vie», en Deux Régimes de fous, Paris, Minuit, 2003, pp. 359-63.

Deleuze, Gilles (1996), «Bartleby o la fórmula» en Crítica y clínica, Barcelona, Anagrama, pp. 109-145.

Deleuze, Gilles (2005), Lógica del sentido, trad. Miguel Morey y Víctor Molina, Barcelona, Paidós Ibérica, S. A. [Logique du sens, París, Les Éditions de Minuit, 1969].

Deleuze, Gilles y GUATTARI, Felix (1997) ¿Qué es la filosofia?, trad. Thomas Kauf, $4^{\mathrm{a}}$ ed., Barcelona, Anagrama, S. A. [Qu'est-ce que la philosophie?, París, Les Éditions de Minuit, 1991].

Derrida, Jaques (1999), «L'Animal que donc je suis (à suivre)», en L'Animal autobiographique: Autour de Jacques Derrida, Paris, Galilée, 251-301.

Derrida, Jaques (2005), De la gramatología, trad. Oscar del Barco y Conrado Ceretti, Buenos Aires, Siglo XXI editores [De la grammatologie, Paris, Minuit 1967].

Foucault, Michael (1984), «Vie: Expérience et science», en Dits et écrits, IV, Paris, Gallimard, 1994, 763-76.

Foucault, Michael (2002), Las palabras y las cosas, trad. Elsa Cecilia Frost, Buenos Aires, Siglo XXI editores, 2002 [Les Mots et les choses, Paris, Gallimard, 1966]

García Puchades, Wenceslao (2012), «Alain Badiou y el recomienzo de la Idea de comunismo a partir del althusserianismo, el lacanismo y el maoísmo», Daimon, $n^{\circ} 55$, pp.89-103.

Gillespie, Sam (2003), «Beyond Being: Badiou's Doctrine of Truth», Communication and Cognition, 36(1-2), pp. 5-30.
Hallward, Peter (2003) Badiou: A Subject to Truth, Minneapolis, University of Minnesota Press.

Hardt, Michael y NEGRI, Antonio (2005), Imperio, trad. Alcira Bixio, Barcelona, Paidós Ibérica, S.A. [Empire, Cambridge, Harvard University Press, 2000]

Hardt, Michael y NeGRI, Antonio (2004), Multitud. Guía y democracia en la era del Imperio, trad. Juan Antonio Bravo, Buenos Aires, Debate. [Multitude. War and Democracy in the Age of Empire, Nueva York, Penguin Books, 2004].

Hoens, Dominiek y Pluth, Ed (2004), «Working Through as a Truth Procedure», Communication and Cognition, 37(3-4), pp. 279-92.

Hoens, Dominiek (2003), «The True Is Always New: Essays on Alain Badiou», Communication and Cognition, 36(1-2), pp. 3-4.

Lacoue-Labarthe, Philippe y NANCY JeanLuc (1997), Retreating the Political, ed. de Simon Sparks, Londres y Nueva York, Routledge

Lawlor, Leonard (2006), The Implications of Immanence. Toward a New Concept of Life, Nueva York, Fodham University Press

Lazzarato, Maurizio (2001), Puissances de l'invention, París, Les empêcheurs de penser en rond.

Marchart, Oliver (2009), El pensamiento político posfundacional: la diferencia politica en Nancy, Lefort, Badiou y Laclau. Buenos Aires, Fondo de Cultura Económica [Post-Foundational Political Thought, Political Difference in Nancy, Lefort, Badiou and Laclau, 
Edimburgo, Edinburgh University Press. 2007].

McGee, Patric (2009), Theory and the Common. From Marx to Badiou, Nueva York, Palgrave MacMillan.

Merleau-Ponty, Merleau (1956-1957), La Nature, notes cours du Collège de France, Paris, Le Seuil, 1995.

Nancy, Jean-Luc (2001), La comunidad desobrada, Madrid, Arena Libros [ $\mathrm{La}$ communauté désouvrée, París, Christian Bourgois, 1986]

Nancy, Jean-Luc (2002), La comunidad afrontada, en Maurice Blanchot, La co- munidad inconfesable, Madrid, Arena Libros, pp. 97-120 [La communauté affrontée, París, Galilee, 2001]

Pelbart, Peter Pál (2009), Filosofia de la deserción : nihilismo, locura y comunidad, trad. por Santiago García Navarro y Andrés Bracony, $1^{\text {a }}$ ed., Buenos Aires, Tinta Limón.

Virno, Paolo (2003), Gramática de la multitud, trad. Adriana Gómez, Juan Domingo Estop, Miguel Santucho, Madrid, Traficante de sueños.

\section{NOTAS}

${ }^{1}$ Como referencia fundamental del pensamiento en inmanencia o vitalismo de estos filósofos véase sus últimos escritos, principalmente: Gilles Deleuze, «Immanence: une vie» (1995), Michel Foucault, «Vie: Expérience et science» (1984) y Jacques Derrida, «L'Animal que donc je suis (à suivre)» (1999).

${ }^{2}$ El propio Jean-Luc Nancy nos presenta un ejemplo de estas operaciones aplicadas a la comunidad étnica, la comunidad de amantes, la comunidad cristiana, la comunidad política, etc. (Nancy, 2001, 30-43) .

${ }^{3}$ Por ejemplo, para dar cuenta de esta potencialidad relacional desvinculada de sometimientos instituidos, Agamben y Deleuze se servirán de la figura ficticia de Bartleby, el escribiente raquítico de silueta pálida de Melville, quien de repente, a cada orden que recibe del patrón, comienza a responder: «Preferiría no hacerlo». Sentencia ni positiva ni negativa-comenta Deleuzeque carece de objeto definido como si enunciara lo indecible (Deleuze, 1996; Agamben, 2000). El propio Agamben y los filósofos Antonio Negri y Michael Hardt proponen como figuras reales de esta potencialidad-en-común-sin-forma las revueltas de la plaza de Tiananmen y los movimientos sociales de Pekín, Los Ángeles, Seattle o Porto Alegre (Agamben, 2006, 54-5; Hardt y Negri, 2005, 63-86).

${ }^{4}$ Badiou denomina a este procedimiento de creación infinito en común «procedimiento genérico» 0 «verdad». Para el filósofo francés una verdad es un procedimiento de transformación de la lógica del saber dominante de una situación que está constituido por un conjunto de elementos a los que Badiou denomina su sujeto-cuya consistencia o ser-en-común está determinada por la fidelidad a la lógica de un acontecimiento. Así, en la medida en que un acontecimiento supone una excepción con el saber dominante, no existe lenguaje capaz de determinar sus propiedades, de manera que la «regla de pertenencia» del cuerpo de una verdad es precisamente carecer de determinación (Badiou, 2007a, 230, 371-80, 432; $1998,103)$. Además, como proceso de transformación, el cuerpo de una verdad evoluciona «forzando» a los elementos que pertenecen a la situación para que se incorporen a esta lógica excepcional (2007a, 440-4). Son precisamente estos dos aspectos los que confieren al cuerpo colectivo de un procedimiento verdadero su carácter genérico e infinito: genérico, pues su carencia de propiedades le impide excluir a nadie (2004b, 106); e infinito pues su origen transfor- 
mador impide su clausura, ya que requiere siempre de los elementos a transformar para poder existir (2004b, 121-3; 2007a, 436-7). Para más detalles acerca del concepto de «verdad» de Badiou véanse Hallward (2003: 130-3, 340-8), Clemens (2005), Hoens (2003), Gillespie (2003), y Hoens y Pluth (2004).

${ }^{5}$ Para Alain Badiou el sistema de axiomas ZF, mediante el axioma de vacío, nombrará al vacío con la marca «conjunto vacío». El axioma de vacío aparece así como una declaración de existencia que pone al vacío en uno para poder ser presentado en un conjunto. Dicho axioma nos presenta al conjunto vacío como la porción elemental de existencia de un conjunto, la mínima cantidad de materia, a partir de la cual cualquier conjunto matemático puede ser derivado (2007a, 823). Por otro lado, el axioma de extensionalidad postula que todo lo que existe pertenece a un conjunto. Y como todo conjunto es un múltiple de múltiples, podríamos concluir que sólo podemos declarar la existencia de un múltiple -o elemento- en la medida en que pertenece a otro múltiple: «Existir como un múltiple es simplemente pertenecer a una multiplicidad. Existir es ser-un-elemento-de. No hay otro posible predicado de existencia como tal»» (Badiou, 2002, 130). Con otras palabras, ser presentado como un elemento significa afirmar su pertenencia a un conjunto de elementos. Para una breve explicación de estas teorías véase Hallward (2003: 103-104, 412-420).

${ }^{6}$ El uso táctico de la literatura por parte de la filosofía se incluye dentro de uno de los «esquemas» que representan los modos en los que la filosofía se ha aproximado al arte de lo largo de la historia, a saber, el esquema didáctico. El esquema didáctico nos muestra cómo la filosofía ha acudido al arte como mero objeto capaz de producir falsas verdades con poder de «encantar» a aquellos que las contemplan. Esta operación del arte ha sido denominada mimesis por la teoría del arte. La filosofía, por tanto, se aprovecharía del poder de persuasión de la mimesis para poner su poder persuasivo al servicio de su empresa, a saber, la transmisión igualitaria de la Idea del presente. En otras palabras, la filosofía toma prestado del arte su poder de seducción para orientarlo a sus propios objetivos $(2009,46-7)$.

${ }^{7}$ Por ejemplo, Badiou (2003b) encuentra una de estas figuras en el filme de los hermanos Wachowski, The Matrix. El filme nos muestra cómo el procedimiento de revolución, encarnado por las acciones que llevan a cabo la tripulación del Nebuchadnezzer, es un proceso que se ejecuta en Matrix, provocando nuevas rupturas en el orden simbólico (nuevos fallos en el sistema) para conseguir nuevas incorporaciones a la causa revolucionaria. La tripulación del Nebuchadnezzer representa la figura de un proceso creativo, infinito y siempre abierto a nuevas incorporaciones, cuyo ser-en-común se fundamenta en su oposición a la lógica dominante existente.

${ }^{8}$ Algunos de estos modelos los encuentra Badiou en diferentes filmes. Por ejemplo, la figura ética del artista en busca de nuevas configuraciones formales frente al artista sometido a los condicionamientos del mercado en Passion o en Histoire(s) du cinéma de Godard (Badiou, 2001, 1998); la figura ética de las clases populares capaces de incorporarse a nuevos procesos políticos de emancipación al margen de las formas sindicales o de partido en Tout va bien o en Passion, también de Godard (Badiou, 2005, 2001); y la figura ética de los amantes que se incorporan a un episodio amoroso de Dos a partir de un «encuentro amoroso» frente a la comunión de amantes o los amantes libertinos en Identificazione di una dona de Antonioni o en Chikamatsu monogatari [Los amantes crucificados] de Mizoguchi (Badiou, 2000, 2004a). 